\title{
Impact of COVID-19 on medical education: introducing homo digitalis
}

\author{
Stavros Gravas ${ }^{1}$ (1) $\cdot$ Mumtaz Ahmad $^{2} \cdot$ Andrés Hernández-Porras $^{3} \cdot$ Frederico Furriel $^{4} \cdot$ Mario Alvarez-Maestro $^{5}$. \\ Anant Kumar ${ }^{6} \cdot K_{\text {Ku }}$ Sung Lee ${ }^{7} \cdot$ Evaristus Azodoh $^{8,9} \cdot$ Patrick Mburugu $^{10} \cdot$ Rafael Sanchez-Salas $^{11} \cdot$ Damien Bolton $^{12}$. \\ Reynaldo Gomez ${ }^{13}$. Laurence Klotz ${ }^{14}$. Sanjay Kulkarni ${ }^{15}$. Simon Tanguay ${ }^{16}$. Sean Elliott ${ }^{17}$. Jean de la Rosette ${ }^{18}$ on $^{12}$ \\ behalf of the Office of Education and SIU Board of Directors
}

Received: 2 June 2020 / Accepted: 14 August 2020 / Published online: 29 August 2020

(c) Springer-Verlag GmbH Germany, part of Springer Nature 2020

\begin{abstract}
Purpose To determine how members of the Société Internationale d'Urologie (SIU) are continuing their education in the time of COVID-19.

Methods A survey was disseminated amongst SIU members worldwide by email. Results were analyzed to examine the influence of age, practice region and settings on continuing medical education (CME) of the respondents.

Results In total, 2494 respondents completed the survey. Internet searching was the most common method of CME (76\%; all $p \mathrm{~s}<0.001)$, followed by searching journals and textbook including the online versions $(62 \%$; all $p s<0.001)$. Overall, $6 \%$ of the respondents reported no time/interest for CME during the pandemic. Although most urologists report using only one platform for their CME (26.6\%), the majority reported using $\geq 2$ platforms, with approximately $10 \%$ of the respondents using up to 5 different platforms. Urologists $<40$ years old were more likely to use online literature (69\%), podcasts/AV media (38\%), online CME courses/webinars (40\%), and social media (39\%). There were regional variations in the CME modality used but no significant difference in the number of methods by region. There was no significant difference in responses between urologists in academic/public hospitals or private practice.

Conclusion During COVID-19, urologists have used web-based learning for their CME. Internet learning and literature were the top frequently cited learning methods. Younger urologists are more likely to use all forms of digital learning methods, while older urologists prefer fewer methods.
\end{abstract}

Keywords Coronavirus $\cdot$ COVID-19 $\cdot$ Urology $\cdot$ Medical education $\cdot$ Online learning $\cdot$ Social media

\section{Introduction}

Healthcare professionals are mandated to continuously update their knowledge and skills in order to provide high quality, up to date healthcare to their patients. Physicians face an extremely large amount of new information. This requires ongoing participation in continuing medical education (CME) and a habit of lifelong learning.

As healthcare systems in many countries have been overwhelmed by the COVID-19 pandemic, many physicians have

Electronic supplementary material The online version of this article (https://doi.org/10.1007/s00345-020-03417-3) contains supplementary material, which is available to authorized users.

Stavros Gravas

sgravas2002@yahoo.com

Extended author information available on the last page of the article found themselves either on the frontline, fighting COVID-19 alongside their critical care colleagues, or have suspended their clinical activities as a result of reprioritization of patient care [1]. Inevitably, COVID-19 has also affected the field of urology [2-5].

The pandemic has important consequences to medical education. Major urological meetings have been cancelled or postponed and CME courses that were previously conducted as in-person, face-to-face modes, must now evolve to online or virtual modes of learning. As various forms of lockdown have been implemented globally, many urologists have turned to online digital platforms to practice by telemedicine and continue their medical education remotely. There are a variety of choices of digital teaching and learning formats for medical education [6]. The question we addressed was whether and to what degree the pandemic has altered online CME by urologists. 
To better enhance the continuity of learning for urologists in this time of transition and uncertainty, the Société Internationale d'Urologie (SIU) disseminated a survey to members worldwide, to determine how they are continuing their education in the face of COVID-19. This information would inform planning for future online educational initiatives.

\section{Methods}

\section{Survey design and dissemination}

The Société Internationale d'Urologie currently has 10,018 members in 131 countries. In response to the COVID-19 pandemic, a survey was designed with multiple-choice questions about respondent demographics and practice change. The full survey has been published [7] and is available as Appendix 1 at https://www.mdpi.com/2077-0383/9/6/1730/ s1. The survey was opened March 27, 2020 and closed April 11,2020 . It was administered online using the Aventri ${ }^{\mathrm{TM}}$ platform and distributed via email, using names on the SIU eNews mailing list. The survey included reasons why the survey was conducted and the importance of participation. No compensation was offered for participation. All responses were anonymous. This study is an analysis of the education related questions. Available options for medical education included Internet searching (such as medical databases, blogs or googling for specific information), journals and textbooks (including online versions), podcast/video or audiotapes, online CME courses/webinars, social media (Twitter, Facebook, Instagram or LinkedIn). Indicating no time/interest for this now was also an option. Respondents could select more than one option.

The analysis was conducted between methods for CME used for the total sample, as well as split by age, and practice setting. Regional variations in responses were explored in order to capture evolving changes in the impact of the pandemic as it progressed across the globe.

The number of CME methods urologists use (from 0 to 5 methods), summarized by total sample, and split by age, region, and practice was also analyzed.

\section{Statistical analysis}

The survey data were analyzed in two ways. First, betweensubjects' effects were explored via a series of omnibus Pearson chi-square tests (using a standard alpha threshold of $P=0.05$ ). The chi-square tests were followed-up by calculating, for each cell in each contingency table, an adjusted standardized residual. Conceptually, these are the Z-transformed differences between the expected and observed value for that cell [8]. The larger the adjusted standardized residual, the larger this expected-observed difference, with adjusted standardized residuals that exceed a critical threshold flagging cells with an observed value that is higher or lower than expected given the null hypothesis. The critical threshold was Bonferroni corrected for multiple comparisons within each contingency table.

Second, within-subject effects were explored using McNemar's tests. To reduce the risk of Type I errors with multiple comparisons, critical thresholds were Bonferroni corrected.

\section{Results}

The survey was emailed to 15,252 contacts of SIU and in total, 2494 respondents from 76 countries completed the survey. The response rate was $16.35 \%$. Detailed demographic data of the respondents has been published in detail [7].

\section{Which continuing education methods do urologists use?}

Internet searching was the most common method of continuing education used ( $76 \%$; all $p s<0.001)$, followed by searching journals and textbook $(62 \%$; all $p s<0.001)$. There were no statistically significant differences in the use of podcasts/ AV media (33\%), online CME courses/webinars (36\%), and social media (33\%); all were more common than reporting having no time or interest for continuing medical education (6\%; all $p$ values $<0.001)$.

Most of the urologists reported using $\geq 2$ methods, with approximately $10 \%$ of the respondents using all 5 methods. On the other hand, $26.6 \%$ of the urologists reported using only one method for their CME (Fig. 1). In the subgroup of urologists who use only one method internet searches were reported by half (53.5\%), literature by $25.9 \%$, followed by online courses/webinars (10.7\%). Only $6.2 \%$ and $3.6 \%$ use Social Media and Podcasts/AV media, respectively, as the only method for education.

\section{Are there age differences in the number and type of continuing education methods urologists use?}

There was a difference in the number of learning methods used by age. As age increases less methods are used. Urologists $<40$ years are more likely to use all forms of learning to continue their education (11.2\%) compared to older urologists $(4.2 \%)$. Only one learning method is used by $31.2 \%$ of urologists $>55$ years and $18.8 \%$ of younger urologists.

Younger urologists were more likely than expected to use the literature (69\%), podcasts/AV media (38\%), online 
Fig. 1 Number of methods used by urologists to continue their medical education during COVID-19

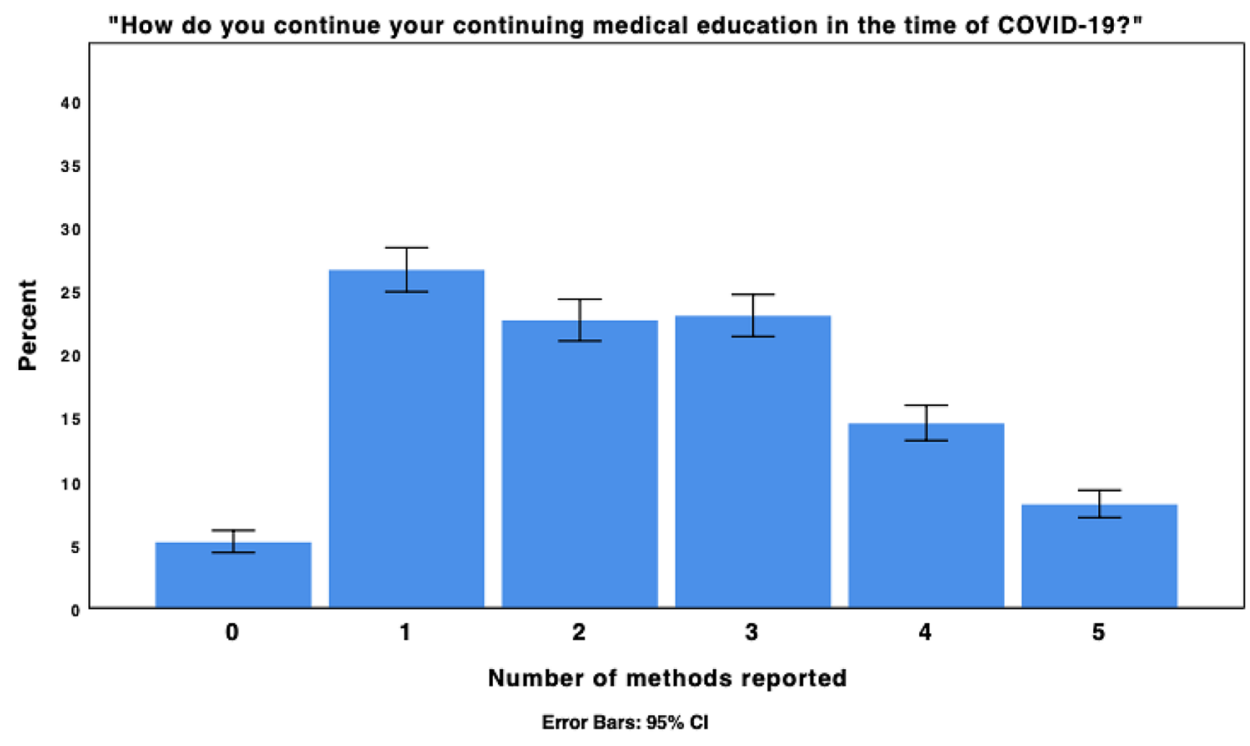

CME courses/webinars (40\%), and social media $(39 \%)$ (adjusted standardized residuals $=5.23,3.99,2.69$, and 5.18 , respectively). In contrast, older urologists are less likely to use literature (56\%), podcasts/AV media $(28 \%)$, and social media (24\%) (adjusted residuals $=-3.73$, $-2.84,-5.66$, respectively). (Fig. 2).

Fig. 2 Preferred CME methods used by urologists grouped by age during COVID-19

\section{Are there regional differences in the number and type of learning method used by urologists during COVID-19?}

There was no statistical difference in the number of learning methods used by region. However, there were regional differences in terms of the type of learning method used. We observed a tendency towards less than expected internet

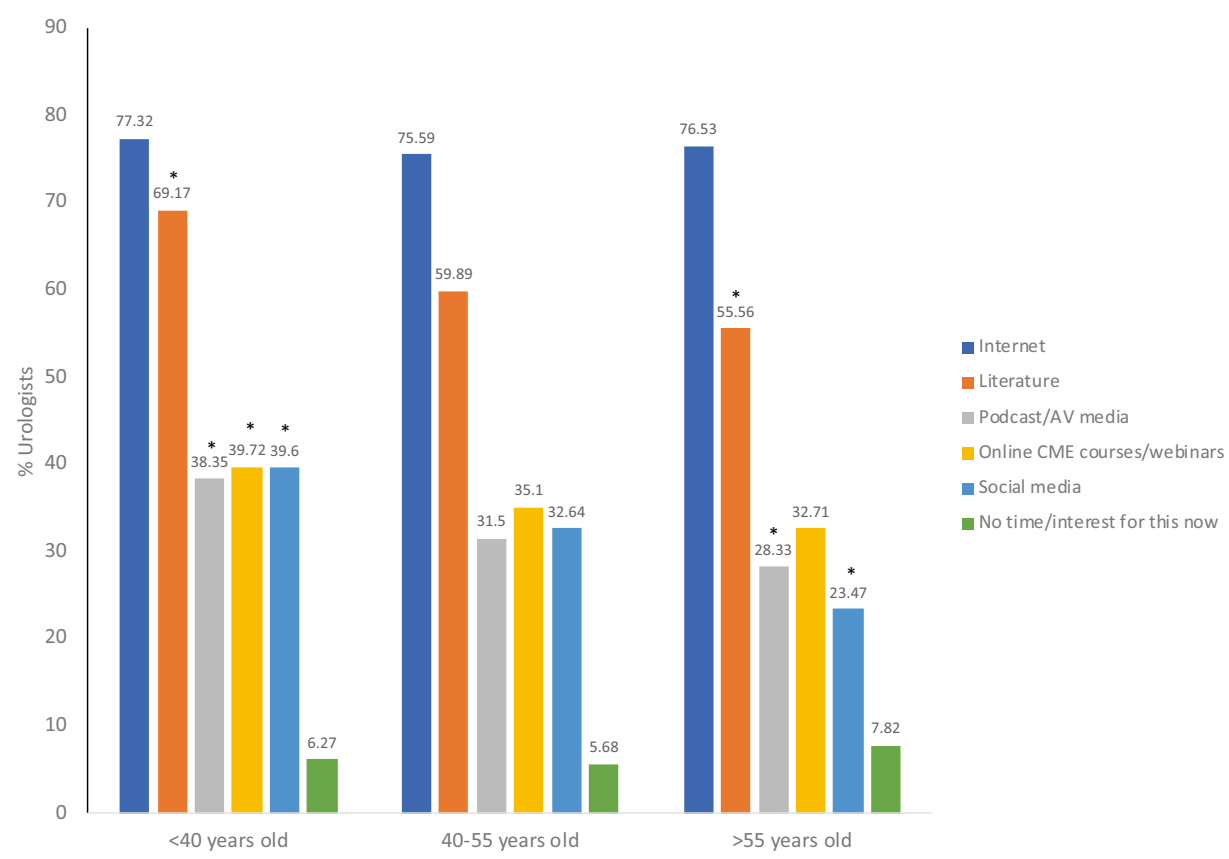

*Indicates statistical significance 
use for education in North America $(p<0.001$, adjusted residual: -3.42 ), less use of literature in West/Southwest Asia ( $p=0.011$, adjusted residual, -3.34$)$, social media use higher than expected in East/Southeast Asia (42.4\% urologists, $p=0$, adjusted residual: 4.88), lower in both Europe $(28.4 \%, p=0$, adjusted residual $=-3.82)$, and in South America (19.7\%, $p=0$, adjusted residual $=-4.01)$. (Fig. 3).

\section{Are there practice setting differences in the number and type of learning method used?}

There was no detected significant difference in the type and number of methods used for learning between those in academic/public hospitals and those with private practice.

\section{Are there differences in the number of urologists who had no time/interest for medical education during COVID-19?}

$6 \%$ of the respondents reported that they had no time/interest for medical education in the face of COVID-19. There was no difference in responses between different age groups and practice settings. Urologists in Europe were more likely than expected to have no continuing medical education (adjusted standardized residual $=4.80$ ). while urologists in East/ Southeast Asia reported a lower than expected percentage (adjusted standardized residual $=-3.92$ ).

\section{Discussion}

Medical education is constantly evolving. More recently, we have been witnessing an increase in the use of social media, podcasts, online courses and webinars. With the advancement in digital technologies, CME activities can now offer more interactive learning formats, allowing learners to tailor their learning methods to their needs [6]. The current COVID-19 pandemic crisis has evidenced the urgent need to have alternative CME methods in place given the reduction in face-to-face meetings.

Digital medical education includes a diversity of methods that can serve different objectives, contexts and learners. Web-based learning cannot be treated as a single entity. Our survey showed that not all methods have met the same acceptance and adoption by the urological community. Internet learning and literature were the top frequently cited learning methods during the COVID-19 pandemic. Different age groups had different approaches to their education. Younger urologists were more likely to use all forms of digital learning methods, while older urologists prefer fewer methods. There were regional differences in terms of the type of learning method used: lower than expected use of internet in North America, literature in West/Southwest Asia, and social media in both Europe and South America. In contrast, a higher than expected use of social media was recorded in East/Southeast Asia. The preferred learning methods are similarly distributed over all practice settings.
Fig. 3 Regional trends in learning methods used by urologists during COVID-19

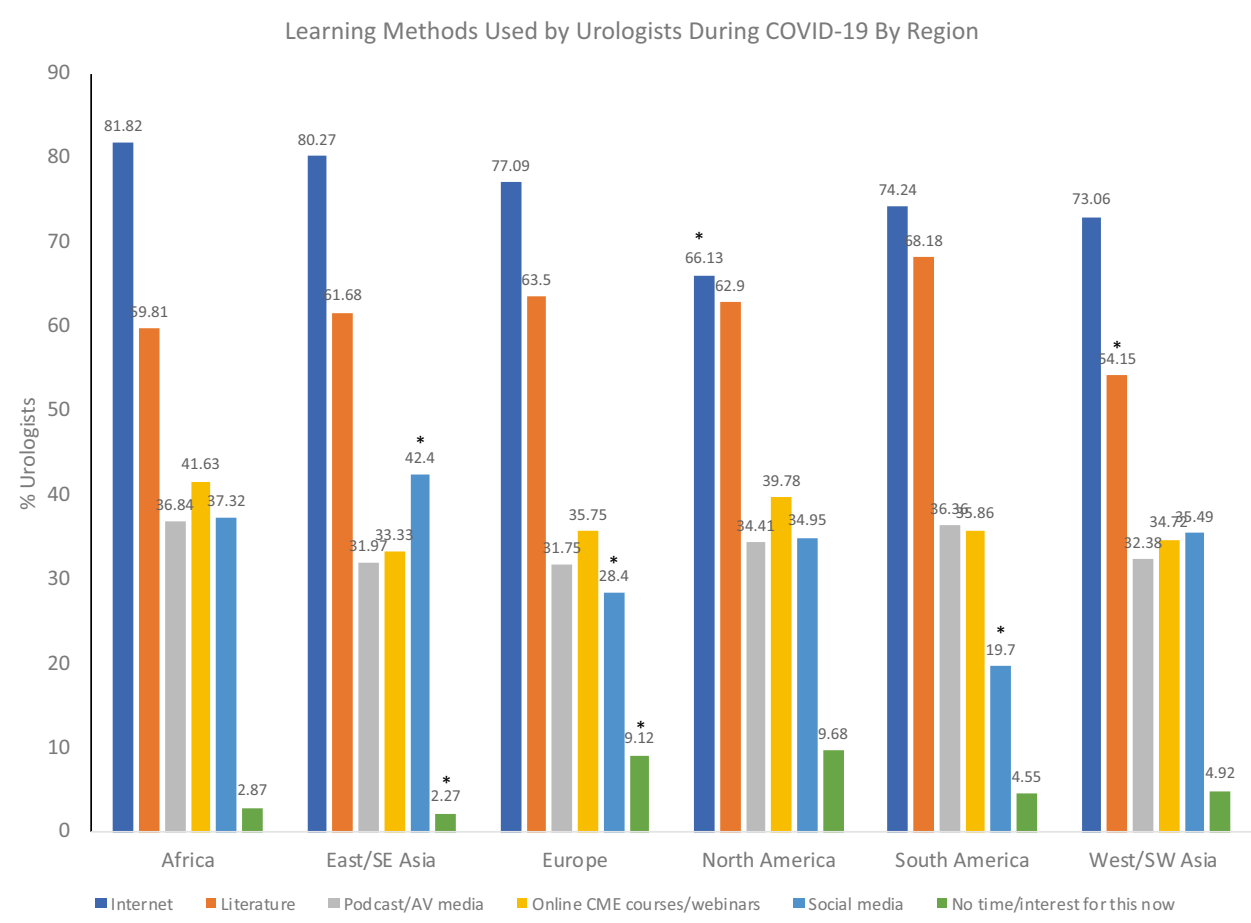


The present global survey suggests that approximately $6 \%$ of urologists have had no time or need in post-graduate education during the pandemic crisis. Urologists in Europe reported a higher than expected percentage while East/ Southeast Asian colleagues had the lowest percentage. Results are likely influenced by regional variation in the severity of the COVID-19 situation and match the spread of COVID-19 from east to west. In East/Southeast Asia, healthcare systems appear to be the closest to returning to normal. Europe was experiencing the peak of the pandemic when the survey was conducted.

The growth of the Free Open Access Medical education (FOAMed) movement which started from emergency medicine and critical care triggered the development of networks and virtual communities of practice which can enable physicians to more quickly share common knowledge $[9,10]$. It is generally agreed that Internet has been reshaping education which will be transformed over the next decade. This is also supported by our surveys showing that internet searching was the most common method of CME used.

Living in a fast-paced world that glorifies speed, has inevitably affected education. A report indicated that $85 \%$ of students who used podcasts for education preferred those that were $30 \mathrm{~min}$ long or less. It was also reported that these students were engaged in another activity while listening to podcasts (e.g. car driving) [11]. This creates uncertainty as to whether podcasts can be used for intensive knowledge acquisition. Learners may be distracted and may not be able to take notes while listening. In addition, most social media such as Twitter, have character limits representing most likely a way to interact and connect with other colleagues, and simply to keep up with the news and most important issues in real-time. Our results showed that only $1.6 \%$ of the respondents use Social Media as the only source of medical education, implying that Social Media cannot be the protagonist in training but can play a supporting role for the dissemination of new evidence.

YouTube ranked as a primary source of educational videos on surgical procedures in a 2018 survey of young urologists in Europe [12]. However, YouTube material is not peerreviewed and may contain biases [13]. Other sources may include Video-sharing via Social Media, and educational video content on digital platforms of scientific organizations (like SIU Academy) and industry.

Formal peer review is mostly absent in FOAMed [10]. Since the production of content is unrestricted, there is a higher risk of inaccurate or biased information. The same holds true for social media since the content may not convey balanced, informed medical knowledge [14]. The European Association of Urology provides recommendations on the appropriate use of social media to help users harness the benefits of social media in a safe and effective manner [15].
Our finding that urologists also turn to literature as a major source for medical education (which also includes online sources) reflects the need for information that is credible and evidence-based. Manuscripts can easily be downloaded and read at their convenience during work or at home. As most journals now provide free online access to COVID-19 articles, this represents an important credible source of knowledge for healthcare professionals.

Didactic sessions alone are less effective in improving overall performance or impacting patient care [16, 17]. Disruption of medical education by the pandemic can affect the pre-clerkship and clerkship learning environments [18]. Medical educators are encouraged to learn from this experience for future crises and prioritize the development of practical strategies to develop curricula using the different learning formats that best meet the needs of the broad spectrum of learners in the urological community.

Online learning has several limitations. It lacks human contact that limits the opportunities for networking and realtime interactive discussions that will help urologists learn from each other in person [19]. Evaluation of web-based learning is performed in very diverse ways mainly focusing on its outcomes or learning aims. However, there is a lack of a standardized content-validated evaluation tool [20].

This study has some limitations. It included self-selected, non-representative and non-random participants. Representation of regions/countries was disproportional and they were at varying phases of the pandemic, therefore, overall results should be interpreted with caution. Our survey did not capture how much time urologists invested in CME, neither were specific sources of each available reply recorded.

This survey maps the evolving landscape of digital medical education globally in the time of COVID-19. Our results define the current position of each learning method and indicate that age is an important factor regarding the number and type of methods used. The era of homo digitalis is rising.

Acknowledgements The authors would also like to acknowledge support from SIU Central Office, including Merveille de Souza, Carrie Thompson, Melissa St-Onge, Susie Petrusa, as well as Christine Albino, for medical writing and editorial support, and Michael Barlev for statistical support.

\section{References}

1. Naspro R, Da Pozzo LF (2020) Urology in the time of corona. Nat Rev Urol 17(5):251-253. https://doi.org/10.1038/s4158 5-020-0312-1

2. Chan VW, Chiu PK, Yee CH, Yuan Y, Ng CF, Teoh JY (2020) A systematic review on COVID-19: urological manifestations, viral RNA detection and special considerations in urological conditions. World J Urol. https://doi.org/10.1007/s00345-020-03246-4

3. Pang KH, Carrion DM, Rivas JG, Mantica G, Mattigk A, Pradere B, Esperto F (2020) The impact of COVID-19 on European 
health care and urology trainees. Eur Urol 78(1):6-8. https://doi. org/10.1016/j.eururo.2020.04.042

4. Puliatti S, Eissa A, Eissa R, Amato M, Mazzone E, Dell'Oglio P, Sighinolfi MC, Zoeir A, Micali S, Bianchi G, Patel V, Wiklund P, Coelho RF, Bernhard JC, Dasgupta P, Mottrie A, Rocco B (2020) COVID-19 and urology: a comprehensive review of the literature. BJU Int 125(6):E7-e14. https://doi.org/10.1111/bju.15071

5. Teoh JY, Ong WLK, Gonzalez-Padilla D, Castellani D, Dubin JM, Esperto F, Campi R, Gudaru K, Talwar R, Okhunov Z, Ng CF, Jain N, Gauhar V, Wong MC, Wroclawski ML, Tanidir Y, Rivas JG, Tiong HY, Loeb S (2020) A Global survey on the Impact of COVID-19 on urological services. Eur Urol. https:// doi.org/10.1016/j.eururo.2020.05.025

6. Cullen MW, Geske JB, Anavekar NS, McAdams JA, Beliveau ME, Ommen SR, Nishimura RA (2019) Reinvigorating continuing medical education: meeting the challenges of the digital age. Mayo Clin Proc 94(12):2501-2509. https://doi.org/10.1016/j. mayocp.2019.07.004

7. Gravas S, Bolton D, Gomez R, Klotz L, Kulkarni S, Tanguay S, de la Rosette J (2020) Impact of COVID-19 on urology practice: a global perspective and snapshot analysis. J Clin Med. https:// doi.org/10.3390/jcm 9061730

8. Agresti A (2013) Categorical analysis. Wiley-Interscience, Hoboken

9. Cadogan M, Thoma B, Chan TM, Lin M (2014) Free Open Access Meducation (FOAM): the rise of emergency medicine and critical care blogs and podcasts (2002-2013). Emerg Med J 31(e1):e7677. https://doi.org/10.1136/emermed-2013-203502

10. Chan TM, Dzara K, Dimeo SP, Bhalerao A, Maggio LA (2020) Social media in knowledge translation and education for physicians and trainees: a scoping review. Perspect Med Educ 9(1):20 30. https://doi.org/10.1007/s40037-019-00542-7

11. Chin A, Helman A, Chan TM (2017) Podcast use in undergraduate medical education. Cureus 9(12):e1930. https://doi.org/10.7759/ cureus. 1930

12. Rivas JG, Socarras MR, Patruno G, Uvin P, Esperto F, Dinis PJ, Roupret M, Borgmann H (2018) Perceived role of social media in urologic knowledge acquisition among young urologists: a european survey. Eur Urol Focus 4(5):768-773. https://doi. org/10.1016/j.euf.2016.11.010
13. Farag M, Bolton D, Lawrentschuk N (2020) Use of YouTube as a resource for surgical education-clarity or confusion. Eur Urol Focus 6(3):445-449. https://doi.org/10.1016/j.euf.2019.09.017

14. Catto JWF (2020) Is social media worth the risk for health care professionals? Eur Urol Focus 6(3):427-429. https://doi. org/10.1016/j.euf.2019.06.003

15. Borgmann H, Cooperberg M, Murphy D, Loeb S, N'Dow J, Ribal MJ, Woo H, Roupret M, Winterbottom A, Wijburg C, Wirth M, Catto J, Kutikov A (2018) Online professionalism-2018 update of European association of urology (@Uroweb) recommendations on the appropriate use of social media. Eur Urol 74(5):644-650. https://doi.org/10.1016/j.eururo.2018.08.022

16. Davis D, O'Brien MA, Freemantle N, Wolf FM, Mazmanian P, Taylor-Vaisey A (1999) Impact of formal continuing medical education: do conferences, workshops, rounds, and other traditional continuing education activities change physician behavior or health care outcomes? JAMA 282(9):867-874. https://doi. org/10.1001/jama.282.9.867

17. Davis DA, Thomson MA, Oxman AD, Haynes RB (1992) Evidence for the effectiveness of CME. A review of 50 randomized controlled trials. JAMA 268(9):1111-1117

18. Rose S (2020) Medical student education in the time of COVID19. JAMA. https://doi.org/10.1001/jama.2020.5227

19. Porpiglia F, Checcucci E, Autorino R, Amparore D, Cooperberg MR, Ficarra V, Novara G (2020) Traditional and virtual congress meetings during the COVID-19 pandemic and the post-COVID-19 era: is it time to change the paradigm? Eur Urol. https://doi. org/10.1016/j.eururo.2020.04.018

20. de Leeuw R, de Soet A, van der Horst S, Walsh K, Westerman M, Scheele F (2019) How we evaluate postgraduate medical e-learning: systematic review. JMIR Med Educ 5(1):e13128. https://doi. org/10.2196/13128

Publisher's Note Springer Nature remains neutral with regard to jurisdictional claims in published maps and institutional affiliations.

\section{Affiliations}

\section{Stavros Gravas ${ }^{1} \mathbb{D} \cdot$ Mumtaz Ahmad $^{2} \cdot$ Andrés Hernández-Porras $^{3}$. Frederico Furriel ${ }^{4} \cdot$ Mario Alvarez-Maestro $^{5}$. Anant Kumar ${ }^{6} \cdot K_{y u}$-Sung Lee ${ }^{7}$. Evaristus Azodoh ${ }^{8,9} \cdot$ Patrick Mburugu $^{10} \cdot$ Rafael Sanchez-Salas $^{11}$. Damien Bolton ${ }^{12}$. Reynaldo Gomez ${ }^{13}$. Laurence Klotz ${ }^{14}$. Sanjay Kulkarni ${ }^{15}$. Simon Tanguay ${ }^{16}$. Sean Elliott ${ }^{17}$. Jean de la Rosette ${ }^{18}$ on behalf of the Office of Education and SIU Board of Directors}

1 Department of Urology, Faculty of Medicine, School of Health Sciences, University of Thessaly, Larissa, Greece

2 Islamabad Medical and Dental College, Islamabad, Pakistan

3 HoPe Urologia, Hospital Angeles/Universidad Autonoma de Baja California, Tijuana, Mexico

4 Department of Urology, Leiria Hospital Center, Leiria, Portugal

5 Department of Urology, Hospital Universitario La Paz, Instituto de Investigación (IdiPAZ), Madrid, Spain

6 Department of Urology, Robotics and Kidney Transplantation, Max Healthcare, New Delhi, India
7 Department of Urology, Samsung Medical Center, Sungkyunkwan University School of Medicine, Seoul, Korea

8 Chivar Specialist Hospital and Urology Centre, Abuja, Nigeria

9 National Hospital Abuja, Abuja, Nigeria

10 Department of Urology, Kenyatta National Hospital, Nairobi, Kenya

11 Department of Urology, Institute Mutualiste Montsouris, Paris, France

12 Department of Urology, Austin Health, University of Melbourne, Melbourne, Victoria, Australia 
13 Hospital del Trabajador, Universidad Andres Bello, Santiago, Chile

14 Division of Urology, Sunnybrook Health Sciences Centre, Toronto, ON, Canada

15 Kulkarni Reconstructive Urology Center, Pune, India

16 Department of Surgery, Division of Urology, McGill University, Montreal, QC, Canada
17 Department of Urology, University of Minnesota, Minneapolis, MN, USA

18 Department of Urology, Faculty of Medicine, Istanbul Medipol University, Istanbul, Turkey 